\title{
A INVENÇÃO DO ESTIGMA TRAVESTI NO BRASIL (1970-1980)
}

\author{
ELIAS FERREIRA VERAS \\ Universidade Federal de Santa Catarina (UFSC) \\ OSCAR GUASCH \\ Universidad de Barcelona (UB)
}

\section{RESUMO}

No presente artigo analisamos como o estigma se transformou em elemento constituidor da representação públicomidiática no processo histórico de construção do sujeito travesti no Brasil. Para realizar a arqueologia dessa invenção histórica, escavamos os discursos da imprensa, entendendo esta como dispositivo de produção de subjetividades que constitui parte da matriz heteronormativa. Relacionamos as peculiaridades dos enunciados produzidos em Fortaleza (CE), na década de 1980, com a produção discursiva sobre o universo trans que circulava nacionalmente no mesmo período. Tal gesto teórico-metodológico nos aproxima do olhar genealógico foucaultiano que persegue as normas discursivas escondidas sob a poeira do tempo-templo que sustentam as invenções históricas.

PALAVRAS-CHAVE: Travestis; Estigma; Contra-discursos.

\section{ABSTRACT}

The aim of this paper is to analyze how, through a historical process, the 'stigma' became the central point of public representation in the construction of the subject transvestite in Brazil. In order to get through the archeology of this historical invention it is important to dig the press speeches, understanding the media as a tool for the creation of subjectivities, constituting the hetero-normative matrix. We analyzed the relation of the peculiar statements made in Fortaleza (CE) during the 1980s with the discursive production of the transsexual universe during the same period. It is a theoretical-methodological gesture drawing us to a genealogic glimpse looking at the discursive norms behind the dust of the temple-time that sustains the historical creations.

KEYWORDS: Transvestites; Stigma; Counter-discourse. 


\title{
Introdução
}

\begin{abstract}
Propus-me a analisar um grupo de jovens e seus parceiros homossexuais adultos. A interação desse grupo de menores com determinada categoria de homossexuais masculinos é analisada, procurando detectar o significado da mesma. Verifico também a natureza dessa relação e como os dois grupos a interpretam, como se apresentam e vêem a situação. Especialmente em relação às categorias de homossexuais, procuro detectar como convivem com seu estigma e se vêem a si mesmos ${ }^{1}$.
\end{abstract}

O trecho anterior encontra-se nas primeiras páginas da dissertação Reis e Rainhas no Desterro: um estudo de caso, da pesquisadora Regina Maria Erdmann, produzida na década de 1980, na Universidade Federal de Santa Catarina (UFSC). Nessa etnografia pioneira sobre o sujeito travesti, a autora estudou a interação entre um grupo de jovens e seus "parceiros homossexuais adultos". Entre estes últimos estavam aqueles que se definiam como travestis. Etnografia que se converteu em História².

O trabalho de Erdmann é um registro histórico da representação hegemônica acerca do sujeito travesti no início dos anos de 1980 no Brasil: "o" travesti, tratado à época no masculino ${ }^{3}$, pertencia a uma determinada categoria de homossexuais que conviviam com um estigma ${ }^{4}$. Contudo, ainda que a pesquisa da referida autora continue considerando as experiências homossexuais (e travestis) como estigmatizadas, é inegável que os enunciados produzidos pelo seu trabalho inauguraram novos lugares de enunciação e de denúncia, ao possibilitar, por exemplo, que seus/as interlocutores/as protagonizassem o verbo, elaborando discursos sobre si, marcados pela pluralidade dos modos de experimentar a travestilidade ${ }^{5}$.

\footnotetext{
${ }^{1}$ ERDMAN, Regina Maria. Reis e rainhas do desterro: um estudo de caso. Dissertação (Mestrado em Antropologia), Universidade Federal de Santa Catarina, Florianópolis, 1981, p. 01.

${ }^{2}$ Essa ideia está presente no Prefácio da primeira edição do livro $A$ Construção da Igualdade, elaborado por Peter Fry, no qual se lê: "(...) as etnografias, tantas vezes escritas 'no presente etnográfico', serão sempre textos históricos, cujo significado será dado pela perspectiva social, cultural e historicamente distante dos seus leitores". MACRAE, Edward. A Construção da Igualdade: identidade sexual e política no Brasil da "Abertura". Campinas: Editora da Unicamp, 1990, p. 11.

${ }^{3}$ No trabalho de Erdmann, assim como na maioria das fontes da década de 1980 consultadas, 0 termo travesti aparece associado ao gênero gramatical masculino. Contudo, observa-se, nos últimos anos, a utilização do termo na flexão feminina, especialmente entre as travestis que militam no movimento trans (travestis e transexuais) e nos recentes estudos acadêmicos sobre esses sujeitos. No primeiro caso, a utilização da flexão feminina acena para o processo de construção do gênero feminino no processo de subjetivação trans, enquanto, no segundo, para o reconhecimento entre os/as pesquisadores/as, da afirmação do gênero feminino como uma das principais reivindicações do movimento trans. Ao empregar o termo no feminino, exceto na transcrição das fontes históricas, buscamos valorizar o processo de construção das subjetividades trans, reconhecendo como uma das principais reivindicações discursivas trans.

${ }^{4}$ GOFFMAN, Erving. Estigma. Rio de Janeiro: LTC, 2012.

${ }^{5}$ A utilização da palavra travestilidade sugere que as subjetividades trans estão atravessadas por multiplicidades, que o termo travestismo, dado seu caráter patologizante, não contempla.
} 
Esse protagonismo do verbo tornou mais difusas as tentativas de homogeneização da imagem travesti produzida pelo pensamento heterossexual ${ }^{6}$. Contra-discursos que se constituem de ditos e de não-ditos dispersos nos fragmentos de "vidas infames" que, ao se encontrarem com o poder", ou melhor, com os múltiplos poderes que constituem os dispositivos da heteronormatividade, assumiram visibilidade na História.

Enquanto Erdmann empregou a categoria sociológica estigma para explicar interações entre jovens e homossexuais, inserindo seu estudo na área do "comportamento desviante", o que revela os ecos do pensamento de E. Goffman e Howard S. Becker nas ciências sociais brasileiras, também nos apropriaremos deste conceito. Todavia, se para a autora parecia não restar dúvidas de que travesti integrava uma categoria de homossexuais estigmatizados, neste artigo, estamos interessados em analisar como o estigma se transformou em elemento constituidor da representação público-midiática no processo histórico de construção do sujeito travesti no Brasil, e ainda, que contra-discursos foram elaborados na denúncia desse estigma. Tal gesto teórico-metodológico nos aproxima do olhar genealógico, conforme pensando por Michel Foucault ${ }^{8}$, que persegue as normas discursivas escondidas sob a poeira do tempo-templo que sustentam as invenções históricas.

Para realizar a arqueologia dessa invenção histórica, ou seja, da emergência do sujeito travesti público-midiático como sujeito estigmatizado, escavamos os discursos da imprensa como parte constituinte do dispositivo heteronormativo. Relacionamos as peculiaridades dos enunciados produzidos em Fortaleza (CE), na década de 1980, nos dois maiores jornais em formato impresso da cidade - O Povo (OP) e Diário do Nordeste (DN) -, com a produção discursiva sobre o universo trans ${ }^{9}$, que circulava nacionalmente.

Quais representações sobre o universo trans foram produzidas por esses discursos? Como os sujeitos que reivindicavam uma identidade travesti se apropriaram dessas representações? À primeira questão, respondemos que a grande imprensa de Fortaleza, mas também de outras cidades do Brasil, lançaram seu olhar, sobretudo, para a prática da prostituição travesti, produzindo um sujeito travesti marginal que assume visibilidade através de

\footnotetext{
${ }^{6}$ No começo dos anos de 1980, a filósofa, poeta e ativista lésbica Monique Wittig revolucionou o campo dos estudos feministas com a publicação do texto 0 pensamento heterossexual (1978), no qual analisava a heterossexualidade, não como prática sexual, mas, sobretudo, como regime político. Wittig definia o pensamento heterossexual como dispositivo político que se constitui por meio de discursos que produzem e instauram heteronormas em matéria de sexo e de gênero. WITTIG, Monique. El pensamiento heterosexual y otros ensayos. Madrid: Egales, 2006.

7 A vida dos homens infames. In: FOUCAULT, Michel. Estratégia, poder-saber. Ditos e escritos IV. Rio de Janeiro: Forense Universitária, 2003, p. 203-222.

${ }^{8} \mathrm{O}$ genealogista sabe que "atrás das coisas há 'algo inteiramente diferente': não seu segredo essencial e sem data, mas o segredo que elas são sem essência, ou que sua essência foi construída peça por peça a partir de figuras que lhe eram estranhas". Nietzsche, a genealogia e a história. In: FOUCAULT, Michel. Microfísica do poder. Rio de Janeiro: Graal, 2005, pp. 15-37.

9 BENEDETTI, Marcos Renato. Toda feita: o corpo e o gênero das travestis. Rio de Janeiro: Garamond, 2005.
} 
notícias relacionadas à "desordem" da cidade: brigas, assassinatos, roubos, etc. À segunda, contestamos que as roupas do estigma não foram vestidas de modo passivo pelos sujeitos.

As travestis costuraram e bordaram com novas linhas de fuga, antigos modelos de masculinidade e de feminilidade, ofuscando as verdades estabelecidas do sistema sexo/gênero ${ }^{10}$, moldado pela ideia de que existe um homem e uma mulher de "verdade". Elas também redesenharam os espaços da cidade através de outras ocupações dos lugares públicos, reorganizando antigas noções do público e do privado. Nesse sentido, a produção da travesti como sujeito estigmatizado, buscou ocultar o caráter de resistência das experiências trans aos processos normatizadores do gênero e da cidade.

\section{Travesti: estigma e abjeção}

De acordo com o sociólogo Goffman, os sujeitos estigmatizados são aqueles/as inabilitados/as a uma plena aceitação social. Para ele, os estigmatizados não são completamente humanos, por isso "construímos uma teoria do estigma; uma ideologia para explicar a sua inferioridade e dar conta do perigo que ela representa, racionalizando, algumas vezes, uma animosidade baseada em outras diferenças, tais como as de classe social" ${ }^{\prime 11}$.

As travestilidades têm sido interpretadas pelo dispositivo heteronormativo como experiências desprovidas de humanidade. Porém, ao serem representadas através da marca do não humano, tais experiências revelam um paradoxo: a constituição de um sujeito que, todavia, não está constituído de humanidade, mas que forma o exterior constitutivo relativamente ao domínio do sujeito.

Assim, aproximamos a categoria estigma da noção de abjeção, ${ }^{12}$ não apenas porque ambas, em diferentes momentos das ciências sociais, foram utilizadas para analisar as travestilidades, mas por serem palavras-ações que constituem os discursos instauradores de sentidos produzidos pela matriz heterossexual acerca das experiências dos sujeitos travestis. Como esclarece a filósofa contemporânea Judith Butler, o abjeto designa aquelas zonas inóspitas e inabitáveis da vida social, densamente povoadas por aqueles que não gozam do status de sujeito, mas cujo habitar sob o signo do inabitável é necessário para que o domínio do sujeito seja circunscrito.

\footnotetext{
${ }^{10}$ Para o entendimento do conceito de sistema sexo/gênero, ver: RUBIN, Gayle. O tráfico de mulheres. Notas sobre a 'Economia Política' do sexo. Tradução de Christine Rufino Dabat. Recife: SOS Corpo, 1993.

${ }^{11}$ GOFFMAN, 2012, p. 08.

${ }^{12}$ Conforme proposta por Judith Butler em: BUTLER, Judith. Cuerpos que importan: sobre los límites materiales y discursivos del "sexo". Buenos Aires, Barcelona, México: Paidós, 2002. Problemas de Gênero: feminismo e subversão da identidade. Rio de Janeiro: Civilização Brasileira, 2008.
} 
A episteme histórica, ${ }^{13}$ que conforma os discursos de emergência acerca do sujeito travesti, foi marcada pela produção discursiva heteronormativa de um sujeito travesti marginal. As marcas do estigma serão localizadas no corpo ambíguo e indeterminado - nas entrelinhas desses enunciados esconde-se a ideia de que as travestis apresentam um excesso do gênero; e na prática social que assumirá maior visibilidade na sociedade, ou seja, a prostituição - no nãorevelado dessa visibilidade, vê-se a ideia de que os corpos das travestis são lugares de excessos de vícios.

Esses enunciados (re)atualizaram velhas associações, como aquela entre homossexualidade, patologia e criminalidade, que encontraram novas formas de divulgação e de repercussão nos meios de comunicação. Se a ambiguidade oferece riscos à pureza da ordem sexo/gênero, uma vez que ameaça polui-la, a prostituição representa perigo ao ordenamento da cidade, que aparece nos discursos da grande imprensa como lugar que necessita de policiamento e de limpeza.

\section{Marcas do estigma I: ambiguidade e indeterminação}

O aparecimento de Roberta Close na revista Playboy, em 1984, e a sua repercussão nos meios de comunicação, nos ajudam a pensar como a ambiguidade e a indeterminação foram produzidas pelo discurso midiático como marcas constitutivas do estigma e da abjeção travesti, ao mesmo tempo em que foram tomadas como elementos de fascínio.

Estigma e abjeção travesti encarnam-se no corpo, tal como os hormônios e a prótese de silicone. São, portanto, marcas corporais que se mostram e se escondem através da ambiguidade e da indeterminação. Homem? Mulher? Homossexual? Transexual? Travesti? Surgem como ameaça à pretensa coerência do sistema sexo/gênero, à suposta inteligibilidade dos gêneros e à fictícia verdade das categorias homem/mulher.

O texto que acompanhava o ensaio sensual de Roberta Close na Playboy reservava à modelo um discurso elogioso em que revela o quanto a ideia de fascínio estava atrelada e atravessada pelo discurso estigmatizante, presente, por exemplo, na acusação de que a modelo teria "roubado" o lugar das mulheres mais bonitas:

Raras pessoas provocam curiosidade tão intensa como Roberta Close, que, sendo como é, roubou o lugar das mulheres mais bonitas no último carnaval e anda atrapalhando completamente a cabeça de muitos homens deste país. Como é ela - que se define como uma pessoa transexual? "Uma moça fina e bem educada, que eu teria o maior prazer em convidar para casa,

\footnotetext{
${ }^{13}$ FOUCAULT, Michel. As Palavras e as Coisas: uma arqueologia das ciências humanas. Martins Fontes: São Paulo, 2000.
} 
certa de que encantaria todos os meus amigos", é a opinião do colunável carioca Noelza Guimarães. "Roberta é uma pessoa extremamente gentil e uma profissional de rara competência", acrescenta o produtor Guilherme Araújo. E Suzana de Moraes, filha do poeta e diplomata Vinicius de Moraes, (...) não deixa por menos: "Roberta é delicada e doce, uma grande artista, uma gracinha". O mais entusiasmado, no entanto, parece ser o analista Eduardo Mascarenhas, embora só a tenha encontrado uma vez, rapidamente, numa festa. Ele é definitivo: "Roberta é simplesmente um marco na história social do país. É a primeira pessoa assim que transmite um sentimento de sensualidade e ternura e não o clima habitual de agressividade e ódio pelo que é diferente ${ }^{\prime 14}$.

Um "pequeno detalhe" era lembrado pela publicação como explicação para que La Close tivesse chegado ao "ponto aonde chegou": na sua carteira de identidade, seu nome masculino. O nome masculino da modelo, não foi esquecido pela revista Playboy, mesmo diante dos elogios à sua feminilidade.

A lembrança da ambiguidade de Roberta estava presente em praticamente todas as reportagens dos jornais OP e DN sobre o "fenômeno" Roberta Close, como ficou conhecida a repercussão em torno da modelo. Essa produção discursiva acompanhou o desnudamento do seu corpo e as tentativas de desnudamento de sua "alma" na mídia.

"Pequeno detalhe" que lembrava que o discurso de fascínio alicerçado sobre determinado ideal de beleza feminina e construído em oposição ao estereótipo da travesti marginal estava acompanhado por discursos estigmatizantes. Nesse sentido, seria um engano acreditar que as travestis e transexuais que se aproximavam de uma representação da "mulher de verdade" estivessem plenamente aceitas pela heteronormatividade.

Em 1985, a jornalista Regina Marshall, do jornal OP, recorria a La Close para escrever mais uma de suas colunas, hoje facilmente considerada transfóbica:

\section{A voz do trovão}

Faz muito bem o Sindicato dos Jornalistas do Rio, reclamar uma providência enérgica quanto à presença de Roberta Close no "Jornal de Domingo", da TV Manchete, dando uma de entrevistadora. Que me desculpem a expressão, mas diante da contratação ridícula de tal figura que, além de se passar por mulher, ainda quer dar uma de jornalista, a "press" verdeamarela está descambando para a avacalhação total. De algum tempo para cá, esse pessoal (Roberta Close, Clodovil e similares), antes confinado a salões de cabelereiros, bailes "gays", ou costurando para fora, deu para dar uma de "estrela", transformando-se em cartazes, com espaço livre para deitar e rolar, promovendo e exteriorizando seus problemas ${ }^{15}$.

\footnotetext{
${ }^{14}$ Playboy, 1984, p. 88.

${ }^{15}$ O Povo, fevereiro de 1985 , p. 8.
} 
Regina Marshall acionava a representação da travesti como sujeito que roubava da "mulher de verdade" a feminilidade. Essa mesma ideia de usurpação está presente no elogio dos jornalistas da Playboy à Roberta Close, o que demonstra que fascínio e abjeção constituem a mesma matriz de produção de sentidos acerca das travestilidades. No texto da jornalista, aparece também a ideia do disfarce atrelada às experiências trans que ameaçariam não apenas a "press" verde-amarela, ou seja, a imprensa, mas de modo geral a sociedade.

Interpretadas pelo discurso heteronormativo como experiências que extrapolam o binarismo masculino/feminino, levando alguns/as a falarem em "terceiro sexo", as travestilidades transbordaram ainda o modelo "bicha/bofe", que definiam as relações homoeróticas no Brasil até a década de 1970. As experiências dos sujeitos travestis foram consideradas "excessivas", inclusive, pelo discurso de construção da igualdade levado a cabo pelo nascente movimento homossexual brasileiro, tão próximo do modelo de homossexual assumido norte-americano, tão distante da bicha, do afeminado, da travesti extravagante brasileira.

Os enunciados em torno do "fenômeno" Roberta Close ensinam que quando não há "excesso", parece não existir sujeito travesti. Assim, a ideia de "excesso" de gênero associada à ambiguidade e à indeterminação revelam que os discursos estigmatizantes são constituídos pela matriz heterossexual que produz um domínio de seres abjetos. Esses discursos também interpretaram o corpo e a vivência dos sujeitos travestis no universo da prostituição como lugar do estigma e da abjeção. Esse excesso de gênero parece ter sido atrelado à ideia de um "excesso" de sexualidade.

\section{Marcas do estigma II - Prostituição e criminalidade}

James Green ${ }^{16}$ lembra que, no Brasil, até a década de 1960, a palavra travesti significava um homem "vestido com roupa de mulher", sem a conotação de uma pessoa que trabalhava como profissional do sexo. A partir do final dos anos de 1970, o termo se transformou em sinônimo de homossexual que se prostitui.

De acordo com o historiador, a visibilidade crescente de travestis e de michês pelas calçadas das grandes cidades acarretou uma mudança significativa na paisagem urbana do país, estando relacionada à flexibilidade dos códigos de vestuários, ao crescente número de shows de travestis nos clubes e à democratização do fenômeno do estrelato, que possibilitou que algumas travestis obtivessem retorno financeiro.

Já em Fortaleza, a associação entre travesti e prostituição se tornou mais evidente a partir da década de 1980. Nesse período, a cartografia erótico-

\footnotetext{
${ }^{16}$ GREEN, James. Além do Carnaval: a homossexualidade masculina no Brasil do século XX. São
} Paulo: Editora da UNESP, 2000, p. 404. 
sexual da cidade assume novos contornos com a proliferação de motéis, com o aumento das publicações pornográficas, com a exibição de filmes pornográficos e com 0 surgimento dos primeiros anúncios sexuais disfarçados de "massagistas" ou "acompanhantes" nos classificados dos jornais.

Essa associação está relacionada à formação de um comércio do sexo que se intensifica com o turismo, mas, sobretudo, com a emergência de um discurso disciplinador que defendia a necessidade de policiamento e de limpeza, especialmente das praças localizadas no centro da cidade.

A carta de um leitor enviada à seção de Opinião do jornal OP, publicada em 16 de janeiro de 1990, oferece indícios da trama jornalística que produz um sujeito travesti marginal e perigoso que ameaça o ordenamento da cidade:

Sr. Editor: Depois que a Polícia Militar do Ceará colocou nas ruas centrais de Fortaleza, no horário noturno, a partir das 22 horas, a cavalaria e os cães amestrados, diminuiu bastante 0 número de roubos, assaltos à mão armada, saques e incêndios nas lojas, praticados pelos mirins e travestis, não somente portadores do defeito moral da pederastia, mas finíssimos ladrões. E a prova de que os travestis são periculosos à sociedade é que os mesmos ficam diariamente na rua Duque de Caxias com Senador Pompeu e também na Praça do Ferreira, em grande grupo, assaltando pessoas indefesas. A PMC deve fazer busca de arma nos travestis que andam armados com giletes, navalhas etc. e são um perigo, sobretudo para os turistas desprevenidos ${ }^{17}$.

Não sabemos se Eduardo Carlos, que teve sua carta publicada na mesma página das "opiniões especializadas", era um leitor "real" ou "ficcional". O fato é que seu discurso parecia não deixar dúvidas: "Os" travestis eram "periculosos à sociedade". Quantos/as leitores/as devem ter compartilhado da mesma sensação pela "proteção" policial contra aqueles sujeitos "portadores do defeito moral da pederastia" e "finíssimos ladrões"?

Dois dias antes de publicar a carta de Eduardo Carlos, o mesmo jornal trazia a reportagem "Travestis: nem AIDS preocupa os que fazem ponto em Fortaleza", na qual ficava explícita a associação entre travestis, prostituição e AIDS:

O centro de Fortaleza é palco de inúmeras transas no período da noite. [...] Em busca de clientes, mulheres e travestis lutam pela madrugada na tentativa de adquirir o pão de cada dia em troca de prazer. [...] Cruzamentos de ruas, como a São Paulo com Floriano Peixoto, transformam-se em verdadeiras passarelas. Após as 21 horas, começa o jogo da sedução. [...] O difícil é distinguir quem realmente é homem ou mulher ${ }^{18}$.

${ }^{17}$ O Povo, Travestis, 16 de janeiro de 1990.

${ }^{18}$ O Povo, 14 de janeiro de 1990. 
A reportagem trazia o depoimento de Alcione, de 26 anos, que dizia estar "bom" o mercado para travestis em Fortaleza, embora "ainda fosse fraco", se comparado com o do Sul e Sudeste. O termo garota, assim como o pronome ela, foi empregado no texto jornalístico entre aspas. Afinal, para o discurso jornalístico, pessoas como Alcione não passavam de homens "vestidos de mulher" que integravam uma "legião de travestis". Alcione era representada como uma falsa-mulher. Seu nome feminino, que para ela constituía parte do seu processo de travestilidade e de autoafirmação, aparecia na matéria como prova de seu embuste e disfarce.

O discurso da imprensa associou as experiências dos sujeitos travestis à prática da prostituição, relacionando-as a toda sorte de perigos: assassinatos, roubos e Aids. Nessa trama jornalística se entrelaçam ambiguidade/indeterminação, prática da prostituição, denúncia de ocupação dos espaços públicos e demandas por policiamento e por limpeza. A cidade aparecia como lugar de pureza e de perigo, enquanto isso, as travestis surgiam como sinônimo de perigo e de castigo.

Apesar da repercussão do "fenômeno" La Close na imprensa, que em Fortaleza coincide com a expansão de uma cartografia transhomoerótica como o tradicional Baile de Carnaval do Ginásio Paulo Sarasate, os concursos Miss Gay e os espetáculos protagonizados por travestis e transformistas em boates e teatros -, a visibilidade pública mais frequente acerca desses sujeitos era aquela que os associava à prostituição e crimes.

Assim, ao compararmos o lugar reservado à Roberta Close na imprensa com aquele reservado às travestis, percebemos que a maioria delas tem sua história resumida à prática do crime ao qual aparecem associadas. As travestis são inscritas através de breves linhas, quase sempre acompanhadas por uma fotografia em preto e branco, tão contrastante com as coloridas imagens da revista Playboy.

A ausência de biografia no discurso da grande imprensa é um dos elementos que constitui o dispositivo heteronormativo que produz o sujeito travesti como estigmatizado. Nessa invisibilidade esconde-se a ideia de que, ao não serem reconhecidas como humanas, as travestis, principalmente aquelas pertencentes às camadas populares, não teriam direito a uma biografia, ao final, a uma vida. Somente as que possuíam uma ambiguidade perfeita ou que buscavam se afastar do universo da prostituição, como fez La Close, tinham direito a uma história de vida. Contudo, os sujeitos não reduziram sua dizibilidade à visibilidade/invisibilidade produzida pelos meios de comunicação. A produção discursiva jornalística está atravessada por contra-discursos, nos quais se lê a denúncia do estigma por parte das travestis. 


\section{Contra-discursos: a denúncia do estigma}

Durante a saída do baile para a rua, ou seja, do espaço privado para o espaço público, apenas as travestis que protagonizavam os espetáculos teatrais/bailes de carnaval tinham direito ao protagonismo do verbo. A partir da intensificação da associação entre travesti e prostituição, algumas delas se apropriaram e produziram contra-discursos.

Travestis como Tina Rodrigues, ativista de Fortaleza, assumiam não apenas uma nova identidade sexual, mas, também, vida através do protagonismo do verbo. Esse protagonismo discursivo transformou a mídia em arena de disputa, de denúncia da sociedade heteronormativa e da violência policial. Se, através desses novos discursos as travestis ainda não faziam o "luto do estigma", estratégia político-discursiva surgida nos anos de 1990, a partir da organização da "militância de grupo", elas iniciavam o processo de luta que tornavam visíveis os preconceitos e as violências sofridas cotidianamente.

Em 23 de setembro de 1988, o jornal DN publicou uma reportagem denunciando a repressão policial às travestis nas boates localizadas na "Passarela", na Avenida Duque de Caxias, importante espaço ocupado pelas travestis em Fortaleza. Segundo a matéria, com chamada de capa:

\section{Gays denunciam perseguição da PM no Centro}

Os gays e travestis denunciam que estão sofrendo cerrada perseguição da Policia Militar, numa briga onde vale tudo, desde as humilhações às agressões físicas, passando naturalmente pela extorsão. No maior reduto homossexual da cidade, trecho da Avenida Duque de Caxias, compreendido entre as ruas General Sampaio e Barão de Aratanha, o temor é generalizado. Ali a policia esta recolhendo, de forma indiscriminada, todos os travestis que são encontrados. Eles dizem que não se trata apenas de preconceito, mas de uma atitude policialesca exacerbada, com o cerceamento do direito que tem o cidadão de fazer a sua opção sexual ${ }^{19}$.

A reportagem foi ilustrada por uma fotografia na qual aparecem duas travestis, tendo ao fundo um outdoor com a imagem de um policial e a seguinte frase: "Para você este é um rosto amigo. Para os marginais é a face da lei". O outdoor fazia parte de uma campanha do Governo do Estado do Ceará para melhorar a imagem da polícia perante a opinião pública. Tina foi uma das travestis entrevistadas e fotografadas.

Enquanto na reportagem a maioria dos gays, travestis e transformistas, generalizados sob o termo homossexual, preferia manter o anonimato, Tina falou:

Durante o episódio do último dia 11, a "Miss Simpatia 88", Tina Tunner, 25 anos, comerciário, nunca passou por uma situação tão vexatória - Ficamos expostos ao público como se fôssemos prisioneiros de guerra. Percorremos as ruas da cidade, até a

${ }^{19}$ Diário do Nordeste, 23 de setembro de 1988, p. 17. 
Central de Polícia, e lá dentro eles (os policiais) nos obrigaram a desfilar debaixo de porrada.

A denúncia do estigma aparece de modo explícito na fala de Tina, provando que o discurso da grande imprensa sobre o sujeito travesti não era monotemático. Contudo, na maioria das vezes, esses contra-discursos só podem ser percebidos através de uma análise a contrapelo. Eles estão presentes nas entrelinhas, quase como um sussurro inaudível. Diante do exposto, ou seja, entre o dito e o inter-dito, surge o não-dito que se manifestava através do escândalo como tática de denúncia.

Em 1985, o DN trazia a seguinte matéria:

\begin{abstract}
Travestis quebram a delegacia
Os travestis "Jane" e "Fafá", respectivamente, Antônio Silva Bezerra e Aldenor Lúcio da Rocha, na madrugada de ontem foram presos no Centro de Fortaleza por estarem praticando desordens, enquanto "faziam ponto". O Comando de Operações Militares (Copom) recebeu denúncia por parte de populares que ambos estavam fazendo "strip tease" na via pública. Na prisão um dos policiais empurrou um dos homossexuais, o que foi suficiente para criar uma imensa confusão na hora de eles entrarem no "camburão". (...) Ao chegarem à Secretaria de Segurança Pública, onde funciona a delegacia de plantão permanente, o "espetáculo" voltou a se repetir. Os travestis quebraram os telefones, vidraças das janelas, cadeiras, além de aplicar violentos tapas, arranhões e mordidas em vários policiais que se esforçavam para aplacá-los (...). Apos quebrar o vidro da janela do cartório, "Fafá" ainda cortou os dois braços, tendo que receber atendimento médico ${ }^{20}$.
\end{abstract}

Percebe-se no trecho anterior que o script da imprensa sobre as travestis acusadas de "desordem" em via pública, se repetia: título sensacionalista; foto das travestis presas; nome feminino entre aspas, seguido do nome masculino; associação com a prostituição; violência policial que culminava com as travestis no "camburão" e na prisão; a tática de cortar-se, como estratégia de sobrevivência à violência da prisão; ausência de falas das próprias travestis.

"Jane" e "Fafá" deram um "espetáculo" na delegacia. Fizeram um escândalo, algumas diriam. Ora, o escândalo travesti talvez seja a metáfora mais explícita de sua transgressão às marcas do estigma e da abjeção, pois ao mesmo tempo em que pode ser interpretado pelo dispositivo da imprensa como ato irracional - na fotografia que acompanha a reportagem, as travestis aparecem enjauladas como animais -, ele é, sobretudo, ato político de denúncia.

${ }^{20}$ Diário do Nordeste, 14 de março de 1985, p. 10. 


\section{Considerações finais}

O sujeito travesti que emerge de modo colorido dos bailes de carnaval, dos palcos das boates e teatros, tomado como sinônimo de fascínio e de curiosidade, na medida em que vai deixando de ser personagem e vai assumindo uma identidade aparentemente fixada nas transformações corporais, passa a ser considerado transgressor ao ordenamento do sistema sexo/gênero.

Ao risco de ordenamento dos gêneros, soma-se a ameaça de ordenamento da cidade. Ao "excesso" de gênero, mistura-se o "excesso" de sexualidade. À abjeção por não habitar a inteligibilidade dos gêneros, acrescenta-se a abjeção por habitar e partilhar com outros não-sujeitos as "zonas inóspitas" da cidade, cuja metáfora da noite, como lugar de vivência travesti, mas também do desconhecido e do perigo, parece revelar.

O "fenômeno" Roberta Close aparece como ponto de inflexão nessa representação publico-midiática hegemônica, que produziu um sujeito travesti marginal estigmatizado e abjeto. Mesmo que La Close tenha buscado se afastar do termo travesti, é inegável que a repercussão da sua história contribuiu para que 0 universo trans $\mathrm{e}$ as discussões em torno da sexualidade/homossexualidade assumissem um debate mais amplo e diversificado no Brasil.

Essas disputas marcam a história recente das travestilidades no contexto nacional, seu capítulo sobre a emergência do movimento político e, sobretudo, a trajetória dos sujeitos. Ainda hoje, apesar de toda a luta e resistência trans, a multiplicidade das experiências dos sujeitos travestis e transexuais continua sendo interpretada - pelos dispositivos que constituem a matriz heterossexual, - como lugar de estigma e de abjeção.

Certamente, caberiam aqui algumas reflexões sobre como as experiências travestis, no momento mesmo que emergem como novo sujeito público-midiatizado, elaboraram não somente resistências, mas novas subjetividades. De como esses sujeitos considerados estigmatizados elaboraram estéticas da existência, trabalho de si sobre si, cuja transformação corporal, a reinvenção dos gêneros, a reocupação dos espaços públicos e a construção de novas formas de família e amizade são exemplos.

\section{Sobre os autores}

Elias Ferreira Veras é historiador, doutorando no Programa de Pós-Graduação em História Cultural, Universidade Federal de Santa Catarina (UFSC), onde desenvolve a tese "Além do paetê: produção discursiva e subjetividades travestis em Fortaleza (1970-2000)". Pesquisador do Laboratório de Estudos de Gênero e História (LEGHUFSC), do Grupo de Pesquisas e Estudos em História e Gênero (GPEHG-UFC) e do Grupo de Estudos Foucaultianos (GEF-UECE). E-mail: eliashistoria@yahoo.com.br

Oscar Guasch é historiador e sociólogo espanhol, professor titular da Universidade de Barcelona. Escreveu, entre outros livros, a trilogia da sexualidade composta por La Sociedade Rosa (1996), Héroes, científicos, heterosexuales y gays: Los varones en 
perspectiva de género (2006) e La crisis de la heterosexualidad (2007). Suas pesquisas contribuem de modo significativo para a configuração da sociologia da sexualidade e do campo da história das homossexualidades e das masculinidades na Espanha. Email: oscarguasch@ub.edu

Artigo recebido em 25 de janeiro de 2015. Aprovado em 09 de setembro de 2015. 